\title{
Alternative Biomarkers to Predict Tumor Biology in Hepatocellular Carcinoma
}

\author{
PHILLIPE ABREU ${ }^{1,2}$, RAPHAELLA FERREIRA $^{2}$, VICTOR MINELI $^{3}$, MAURICIO ALVES RIBEIRO $^{2}$, \\ FABIO GONÇALVES FERREIRA ${ }^{2}$, RODRIGO MARTINEZ DE MELLO VIANNA ${ }^{1}$, \\ FLAVIO DANIEL SAAVEDRA TOMASICH ${ }^{4}$ and LUIZ ARNALDO SZUTAN ${ }^{2}$ \\ ${ }^{1}$ Department of Surgery, University of Miami, Jackson Memorial Hospital, \\ Miami Transplant Institute, Miami, FL, U.S.A.; \\ ${ }^{2}$ Department of Surgery, Division of Liver Surgery, \\ Santa Casa of Sao Paulo School of Medical Sciences, Sao Paulo, SP, Brazil; \\ ${ }^{3}$ Faculty of Medicine, Santa Casa of Sao Paulo School of Medical Sciences, Sao Paulo, SP, Brazil; \\ ${ }^{4}$ Department of Surgery, Federal University of Parana, Erasto Gaertner Cancer Center, Curitiba, PR, Brazil
}

\begin{abstract}
Hepatocellular carcinoma (HCC) is the most frequent primary malignant liver tumor, with more than 800,000 new cases diagnosed each year and with high mortality, ranking fourth in the world in cancer deaths. The worst prognosis is related to the late diagnosis, in which the tumor is at an advanced stage and curative treatments are not efficient in terms of increasing overall survival. Currently, screening and monitoring tests based on current guidelines have limited accuracy, which points to the need for the development of new biomarkers that improve HCC detection as well as its early diagnosis. This review will discuss the five phases of development of a biomarker, from its discovery to its application in clinical practice, and indicate the main biomarkers per development phase. Potential emerging technologies such as "Radiomics", "Proteomics" and "Metabolomics" will also be discussed, which should serve as tools for the elucidation of tumor heterogeneity, as well as provide data for future studies on HCC biomarkers.
\end{abstract}

Hepatocellular carcinoma (HCC) is the most frequent primary tumor of the liver, and its incidence is increasing,

This article is freely accessible online.

Correspondence to: Phillipe Abreu, MD, MSc, Ph.D., FACS, Miami Transplant Institute, $1801 \mathrm{NW} 9^{\text {th }}$ Ave $-7^{\text {th }}$ floor, Miami, FL, 33136, U.S.A. Tel: +1 3053551035, e-mail: Dr.PhillipeAbreu@gmail.com

Key Words: Hepatocellular carcinoma, surveillance, screening, diagnosis, biomarkers, tumor biology, liver tumors, review. currently occupying the sixth position among the incidences of all cancers, and the fourth position among cancer-related deaths (1). The prevalence of HCC is higher in men than in women (1). As for the geographical distribution of the disease, HCC has the highest incidence in developing countries, with more than $80 \%$ of cases reported in subSaharan Africa and East Asia as a result of the hepatitis B endemic in these regions; while the incidence has been decreasing in some Eastern countries such as China and Japan due to vaccination programs and treatment of viral hepatitis. Cases of HCC have increased in Western countries, such as the United States, related to the aging population of patients with hepatitis $\mathrm{C}$ and the emergence of non-alcoholic steatohepatitis (NASH) as a chronic liver disease $(2,3)$. The pre-existence of cirrhosis is estimated in $80 \%$ of patients diagnosed with HCC (4), but currently any etiological agent leading to chronic liver lesions and cirrhosis is considered a risk factor associated with the development of $\mathrm{HCC}$, the most common being hepatitis $\mathrm{B}$, hepatitis $\mathrm{C}$, high alcohol consumption and NASH (5).

Once diagnosed, the prognosis of the HCC patient depends, among other factors, on the intention of the treatment: curative or palliative. Among the curative treatments, surgical resection, local ablative therapies and liver transplantation may be indicated, the latter being the most indicated for early stage patients and the one offering the best overall survival $(6,7)$. Other factors that directly influence the patient's prognosis, such as number of lymph nodes involved, presence of metastasis, tumor size and history of hepatitis, the analysis of these factors being important in the definition of survival rates and individualized therapeutic plans (8). 
The development of biomarkers as complementary diagnostic methods and in the follow-up after treatment, has been the object of study in the last two decades, but before their widespread adoption, there are validation phases $(9,10)$. In this review, the development stages of the current biomarkers will be addressed and the most promising ones in the early detection of HCC will be highlighted. Emerging technologies that may assist in the diagnosis of HCC in the coming years, such as artificial intelligence, are also pointed out.

\section{Current Recommendations}

The diagnosis of HCC is made by imaging examinations or liver biopsy, but for early detection of HCC, screening of asymptomatic patients by monitoring tests should be performed. Therefore, the American Association for the Study of Liver Diseases (AASLD) recommends monitoring every 6 months by abdominal ultrasonography, with or without alphafetoprotein (AFP) dosage, in all adults with cirrhosis, except in cirrhotic patients with Child-Pugh C Score who are not on the transplant list (6). Active surveillance then becomes an early detection tool for HCC, which is directly associated with improved survival rates of patients, as demonstrated by the meta-analysis of Singal et al. (11).

Despite the surveillance recommendations, there are flaws in this process (12). In a meta-analysis, Singal tried to characterize the performance of abdominal ultrasound in the detection of HCC and obtained only a $63 \%$ sensitivity in the detection of early-stage tumors, without any statistically significant improvement in sensitivity when associated with the serum AFP examination (13). Lack of screening and follow-up contribute to the detection of HCC in more advanced tumor stages in one-third of the cases; however, the low sensitivity in detecting the tumor in currently available tests represents the most common cause of late diagnosis, suggesting the need for more effective investigation strategies (12).

In Brazil, the Diagnostic and Therapeutic Guidelines for hepatocellular carcinoma were published by the Ministry of Health in 2012, and recommend screening for HCC by abdominal ultrasonography every 6 months, associated or not with AFP dosage, among patients diagnosed with hepatic cirrhosis who may benefit from curative treatments (patients classified as Child-Pugh A-C without comorbidities) (14). The diagnosis can be preferably made by radiological methods such as computed tomography, magnetic resonance imaging or contrast ultrasonography, reserving the anatomopathological diagnosis to non-cirrhotic patients and to cases in which the radiological methods are inconclusive (14). Screening patients in risk groups is the best way to ensure an early diagnosis and the possibility of healing, and increase the overall survival of these patients (15).

\section{Development of Biomarkers}

A biomarker can be defined as an objective and quantifiable feature of a biological process $(16,17)$. In practice, we can define it as a clinical sign, a parameter observed by the physician, which can be precisely measured and which can be reproduced, and can be used in cancer screening, in measuring therapeutic response or in defining prognosis (17). In HCC, biomarkers are widely applied, whether in decision making for a therapeutic choice or in the selection of patients most likely to get the best results from different treatments (18). The development of potential biomarkers for HCC faces challenges, mainly due to the tumor heterogeneity in this cancer, which makes its clinical applicability difficult $(16,18)$. Recently, gene expression analysis of known potential biomarkers of HCC was used to correlate their expression in tumoral tissues with tumor prognosis (16).

The expansion of studies on biomarkers as monitoring tools led to the establishment of the Early Detection Research Network (EDRN) by the National Cancer Institute (NCI), with the objectives of coordinating research among the biomarker development and validation laboratories, in order to maintain rigor and promote collaboration among them, generating greater efficiency in the studies $(10,19)$. With the objectives of EDRN as a basis, Pepe et al. categorized the development of biomarkers into five phases, from their discovery to their application, as a monitoring tool in the early detection of cancer (10).

Phase 1. Phase 1 development usually begins with preclinical studies, comparing tumor tissue with non-tumoral tissue (10). The objective is to identify unique characteristics of tumor tissues that may lead to a candidate biomarker (10). Techniques such as immunohistochemistry, western blot and more recent technologies such as gene expression profiles based on mass spectrometry have been used to identify genes or proteins in tumor tissues when compared to control tissues (10). Thus, phase 1 aims to identify and prioritize potential biomarkers (establishing the best case selection and control for the development of studies), establish reliable and reproducible assays, determine how well the biomarker in question distinguishes case and control, analyze data obtained and conduct other confirmatory studies with new tissue samples (10).

Phase 2. Phase two consists of clinical trials executed with samples obtained in a non-invasive manner (10). The choice of samples, as well as their sizes, needs to be carefully considered, and even if blood bank samples are used, it is recommended that the final conclusions be obtained from studies with population samples (10). The clinical trials should be performed to show the ability of the biomarker to distinguish between the samples with and without cancer, 
thus allowing it to be considered promising for screening (10). An ideal biomarker for early detection of cancer should be highly sensitive, which indicates that the main objective of phase 2 is estimate the true-positive and false-positive rates in the trial and the ability of the biomarker to distinguish between samples with and without cancer, in addition to optimizing procedures to ensure the reproducibility of the trial in other laboratories (10). Phase 2 has other important objectives, such as evaluating the variations in the levels of the biomarker in question based on clinical-epidemiological factors of the individuals, such as age, gender and also based on tumor characteristics, such as histology, tumor staging and prognosis (10).

Phase 3 . The main objective of phase 3 is to evaluate the ability of the biomarker to identify the disease before clinical diagnosis and thus, define a criterion for a positive test (10). Analyzing the group of cases, a biomarker whose levels change months before the diagnosis of the disease has more potential to become a useful tool in early detection when compared to a biomarker whose levels change days before the diagnosis (10). In this way, this capacity is evaluated and a criterion is defined to classify the test as positive (10). In addition, this phase aims to explore the impact of variables such as demographic factors, characteristics associated with the disease and clinical information of individuals on the discriminatory ability of the biomarker and, in case the biomarker performs better in certain subgroups, assist in the development of prospective studies of phase 4 (10).

Phase 4. Phase 4 consists of a prospective study, in which the objective is to describe the characteristics of the tumor detected by the screening test and these characteristics with possible benefits offered by early detection (10). The samples in this phase should be chosen based on a population that is possibly the target of the screening, that is, a group at risk for development of the disease, which will improve the performance of the biomarker when compared to phase 3 (10). Based on the results obtained, the receiver operating characteristics of the screening test are determined, such as the true-positive rate (proportion of those tested positive versus those that have the disease) and the falsepositive rate (proportion of those who tested positive versus those that do not have the disease) (10).

Phase 5. Phase 5 assesses whether screening reduces mortality from the disease (10). Even when there is early detection of the disease, there may be no benefits for the specific population (10). The reasons for this may be related to ineffective treatment of the detected tumors, difficulties in implementing screening programs or overdiagnosis (10). This phase also considers cost-benefit information, assesses compliance with screening and compares the different approach protocols in the treatment of screened diseases in relation to their effects on mortality and cost (10).

\section{Biomarkers for HCC per Development Phase}

Table I presents the main biomarkers per study development phase for $\mathrm{HCC}$ as well as their applications and initial results.

Phase 1. MicroRNAs. MicroRNAs (miRNAs) are posttranscription gene regulators, which silence messenger RNA and thus, play a homeostatic role by adjusting protein translation, while their deregulation is related to tumor progression (20). The potential of 19 circulating microRNAs as biomarkers for HCC has been studied by Huang et al. (21). In this meta-analysis, when the ability of the marker to differentiate between HCC patients and control group individuals was evaluated, the sensitivity and specificity of miRNA-21 was $86.6 \%$ and 79.5 , respectively, while miRNA122 obtained a sensitivity of $68 \%$ and specificity of $73.3 \%$ (21). Huang et al. have studied the ability of miRNA to differentiate between patients with HCC and hepatic cirrhosis (22). They obtained 16 miRNAs with a statistically significant difference between groups, namely miRNA-15a, miRNA-21, miRNA-29a, miRNA-30c, miRNA-486-3p, Let-7g, miRNA122, miRNA18a, miRNA-338-3p, miRNA-126, miRNA-222, miRNA-223, miRNA-26a, miRNA192, miRNA-27a and miRNA-124 (22). In the recent study by Wu et al., serum levels of miRNA-199a in patients with HCC were significantly lower than those in patients with hepatic cirrhosis, pointing to its potential as a marker for the diagnosis of HCC (23). Thus, the study of microRNAs becomes a useful tool for the development of HCC markers (20).

Metabolomics. Metabolomics is a field of study that aims to provide information about endogenous metabolites in a biological sample, and with these data one can map biochemical changes in a disease and thus develop potential predictive biomarkers (24). Intracellular and extracellular metabolic changes, as well as metabolic pathways, are associated with tumor progression and reprogramming of the microenvironment caused by tumor growth (25).

Recent advances in the Metabolomics field can provide several new types of markers for HCC (26). Wang et al. have proposed an analysis of metabolic profiles based on high efficiency liquid chromatography (UPLC) and mass spectrometry (MS) of samples of HCC patients with cirrhosis of the liver and healthy individuals (27). The metabolic profile showed $100 \%$ sensitivity and specificity in differentiating HCC patients from those with hepatic cirrhosis, and 79.3\% sensitivity and $100 \%$ specificity in the diagnosis of HCC. In addition, the analysis of the profiles indicated 13 potential biomarkers suggestive of metabolic disorders, such as phospholipid and organic acid alterations, in patients with 
Table I. Biomarkers available in the studies of HCC.

\begin{tabular}{|c|c|c|c|c|}
\hline Phase & Biomarker & Application & Results & Author \\
\hline \multirow[t]{9}{*}{ PHASE 1} & miRNA 21 & Differentiation between HCC patients and control group & SN: $86.6 \%$ SP: $79.5 \%$ & Huang et al. (21) \\
\hline & miRNA 122 & Differentiation between HCC patients and control group & SN: $73.3 \%$ SP: $79.5 \%$ & Huang et al. (21) \\
\hline & miRNA & Differentiation between $\mathrm{HCC}$ and $\mathrm{CH}$ patients & $\begin{array}{l}16 \text { miRNA as potential } \\
\text { biomarkers }\end{array}$ & Huang et al. (22) \\
\hline & miRNA 199a & $\mathrm{HCC}$ diagnosis in $\mathrm{CH}$ & $\begin{array}{l}\text { Significantly lower serum } \\
\text { values in HCC patients }\end{array}$ & Wu et al. (23) \\
\hline & Metabolomics & Differentiation between $\mathrm{HCC}$ and $\mathrm{CH}$ patients & SN: $100 \%$ SP: $100 \%$ & Wang et al. (27) \\
\hline & & HCC diagnosis & SN: $79.3 \%$ SP: $100 \%$ & Wang et al. (27) \\
\hline & & Differentiation between $\mathrm{HCC}$ and $\mathrm{CH}$ patients & Potential in early diagnosis & Luo et al. (28) \\
\hline & Proteomics & $\mathrm{HCC}$ diagnosis in patients with $\mathrm{AFP}<20 \mathrm{ng} / \mathrm{ml}$ & HCC detection rate: $89 \%$ & Wang et al. (31) \\
\hline & Radiomics & Recurrence Forecast & AUC predictive: 0.83 & Zhou et al. (35) \\
\hline \multirow[t]{6}{*}{ PHASE 2} & hs-AFP-L3 & HCC diagnosis in patients with $\mathrm{AFP}<20 \mathrm{ng} / \mathrm{ml}$ & SN: $41.5 \%$ SP: $85.1 \%$ & Toyoda et al. (45) \\
\hline & $\mathrm{Dkk} 1+\mathrm{AFP}$ & HCC diagnosis & SN: $80 \%$ SP: $87 \%$ & Li et al. (48) \\
\hline & $\mathrm{Gpc} 3+\mathrm{CD} 34$ & $\begin{array}{l}\text { Differentiation between patients with HCC and } \\
\text { benign hepatic lesions }\end{array}$ & $\mathrm{SN}: 82 \%$ & Enan et al. (54) \\
\hline & AFU & Differentiation between patients with $\mathrm{HCC}$ and $\mathrm{CH}$ or $\mathrm{HC}$ & SN: $90 \%$ SP: $97.5 \%$ & Montaser et al. (57) \\
\hline & Scca-IgM & HCC diagnosis & SN: $89 \%$ SP: $50 \%$ & Pozzan et al. (59) \\
\hline & GP73 & HCC diagnosis & SN: $78.3 \%$ SP: $85.4 \%$ & Jiao et al. (63) \\
\hline \multirow[t]{8}{*}{ PHASE 3} & OPN & $\mathrm{HCC}$ diagnosis in $\mathrm{CH}$ or $\mathrm{CH}$ and AFP patients $<20 \mathrm{ng} / \mathrm{ml}$ & SN: $78.26 \%$ SP: $80.45 \%$ & Zhu et al. (66) \\
\hline & $\mathrm{OPN}+\mathrm{AFP}$ & HCC diagnosis & SN: $88.12 \%$ SP: $74.21 \%$ & Zhu et al. (66) \\
\hline & OPN & HCC diagnosis & SN: $79.21 \%$ SP: $79.24 \%$ & Zhu et al. (66) \\
\hline & MDK & HCC diagnosis & SN: $86 \%$ SP: $75.4 \%$ & Zhang et al. (69) \\
\hline & & HCC diagnosis & SN: $88.5 \%$ SP: $80.6 \%$ & Zekri et al. (70) \\
\hline & & Serum values in $\mathrm{HCC}$ and AFP patients $<20 \mathrm{ng} / \mathrm{ml}$ & $\begin{array}{l}\text { Significantly higher serum } \\
\text { values in } 59.18 \% \text { of patients }\end{array}$ & $\begin{array}{c}\text { Vongsuvanh et al. } \\
\text { (68) }\end{array}$ \\
\hline & DCP & HCC diagnosis & SN: $66 \%$ SP: $88 \%$ & De et al. (72) \\
\hline & GALAD & HCC diagnosis & SN: $91.6 \%$ SP: $89.7 \%$ & Berhane et al. (75) \\
\hline \multirow[t]{4}{*}{ PHASE 5} & $\mathrm{AFP}+\mathrm{US}$ & $\mathrm{HCC}$ diagnosis in $\mathrm{CH}$ & SN: $97 \%$ & Tzartzeva et al. (78) \\
\hline & AFP & Use of AFP cut-off values & $\begin{array}{l}\text { Improved diagnostic } \\
\text { accuracy and } \\
\text { posttreatment follow-up }\end{array}$ & Zhang et al. (81) \\
\hline & & Prediction of liver transplant results & $\begin{array}{l}\text { AFP predictive global survival } \\
\text { after liver transplantation }\end{array}$ & Merani et al. (82) \\
\hline & & Prediction of recurrence after liver transplantation & $\begin{array}{l}\text { Preoperative predictive } \\
\text { global survival AFP }\end{array}$ & Hameed et al. (84) \\
\hline
\end{tabular}

AFP: Alpha-fetoprotein; AFU: alpha-1-fucosidase; AUC: area under the curve; CHC: hepatocellular carcinoma; DCP: descarboxiprothrombin; DKK1: Dickkopf-1; GALAD Scores: acronym for Gender, Age, AFP-L3, AFP, DCP; GP-73: Golgi protein 73; GPC-3: Glipican-3; hs-AFP-L3: alphafetoprotein fucosilate highly sensitive; MDK: midkine; miRNA: micro RNA; OPN: Osteopontine; SCCA-IgM: immunocomplex of squamous cell carcinoma antigen with immunoglobulin M; SN: sensitivity; SP: specificity; US: ultrasonography.

HCC (27). Luo et al. have characterized the serum metabolic profiles of 1448 individuals using UPLC and MS-based methods and a panel was defined after selecting the appropriate biomarkers (28). The ability of the panel to discriminate between HCC and cirrhosis patients was compared with that of the AFP values, and was found to be more efficient (AUC $0.866 v s$. 0.682), revealing its role in early stage HCC screening (28). The analysis of serum metabolites values is a promising tool for predicting metabolic changes at tissue levels due to the tumor installation (25).

Proteomics. Proteomics is an area that studies the complete set of proteins expressed in a cell, tissue or biological fluid (29).
Proteomics, besides determining protein expression profiles, also identifies structure, location, activity, modifications and interactions of proteins in physiological or pathological conditions (29). In HCC, proteomics has the potential not only to elucidate the mechanisms of installation and progression of HCC, but also to provide a basis for the development of biomarkers for the disease (29). Wang et al. have proposed a useful algorithm to predict HCC that associates AFP with 4 other clinical variables, being age, sex, alkaline phosphatase and alanine aminotransferase (30). More recently, they added to the algorithm the biomarker fucosilated kininogen, to improve $\mathrm{HCC}$ detection in early stages and in patients with $\mathrm{AFP}<20 \mathrm{ng} / \mathrm{ml}$ (31). As a result, they obtained AUC greater 
than that of AFP alone (0.977 vs. 0.828), and $89 \%$ HCC detection rate in patients with $\mathrm{AFP}<20 \mathrm{ng} / \mathrm{ml}$ (31).

Gao et al. have conducted a proteogenomic HCC characterization in patients with hepatitis B (32). They found two enzymes, PYCR2 and ADG1A, which can be potential biomarkers for the prognosis of HCC, and observed lower expression of hepatitis $\mathrm{B}$ virus proteins and receptors in patients with HCC suggesting that metabolic changes are related to the advanced stage of the disease and worse prognosis, and may serve as a basis for future studies on HCC treatment (29). In general, proteomic data can provide information that helps in the clinical, biological and therapeutic understanding of HCC (29).

Radiomics. Radiomics is an emerging field that is based on the conversion of images from exams such as computed tomography and magnetic resonance imaging into high dimension data, which are analyzed by artificial intelligence to reveal hidden pathophysiological characteristics that, when added to the patient's characteristics, function as a prognostic or diagnostic tool (33). Regarding HCC, "omics" although at embryonic stage, it has presented promising results (34). Zhout et al. published a study with 215 patients to predict early recurrence of HCC based on the radiomic characteristics of the patients and obtained a predictive AUC of 0.83 in a combined model, showing that the Radiomics signature may be promising in predicting early recurrence (35). Zheng et al. have reported that the combination of factors obtained from the Radiomics model with clinical variables of the patients has good performance in predicting microvascular invasion after HCC resection (36). Radiomics has shown promise in diagnosis, choice of therapeutic treatment, screening evaluation and prognosis of HCC (37).

\section{Polo-like Kinase Proteins}

Polo-like kinase proteins (PLK) are characterized by an Nterminal serine/threonine kinase domain, highly conserved at one or two polo boxes in the C-terminal region, which are crucial for subcellular location, specific phospho-peptide binding and centrioles duplication (38). PLK-4 shows cytoplasmic expression in most human tissues. The protein is located in centrioles and microtubules, and regulates the duplication of centrioles during the cell cycle. Also, tissue expression of PLK-4 is very variable among human tissues, and depends on the number of cells with a high concentration of centromeres, which is directly related to the cellular function of tissues during cell division (39). It is considered a prognostic marker in colorectal cancer (favorable), lung cancer (unfavorable) and pancreatic cancer (unfavorable) (39). In HCC, low expression of PLK-4 is possibly adversely associated with global and disease-free survival in preclinical models $(38,40-43)$.
Phase 2

AFP-L3. AFP-L3 is an AFP isoform and its percentage relative to the total AFP has been used as a marker for HCC detection, with a cut-off value of $10 \%$ (44). In the study by Toyoda et al., hs-AFP-L3 (highly sensitive AFP-L3) was tested in HCC patients under surveillance with AFP values below $20 \mathrm{ng} / \mathrm{ml}$ (45). As a result, for cut-off value of $5 \%$ of hs-AFP-L3 relative to total AFP, sensitivity $41.5 \%$ and specificity $85.1 \%$ in diagnosis of patients with AFP $<20$ $\mathrm{ng} / \mathrm{ml}$ were obtained (45). In that study, the relationship between the percentage of hs-AFP-L3 and prognosis was also evaluated, showing that the measurement of hs-AFP-L3 before treatment can help predict prognosis and define therapies (45). Thus, it has been shown that hs-AFP-L3 may be useful in the early detection of HCC in patients with AFP $<20 \mathrm{ng} / \mathrm{ml}$, having improved sensitivity when combined with Des-carboxy-prothrombin, and may be part of pretherapy as a diagnostic predictor (45).

Dickkopf-1 (DKK-1). DKK-1 is a glycoprotein that acts as an inhibitor of the Wnt/beta-catenine signaling pathway (46). Shen et al. have shown significantly higher serum DKK-1 levels in HCC patients when compared to healthy individuals with chronic hepatitis B or liver cirrhosis (47). In the metaanalysis of Zhenije et al., the combination of DKK-1 and AFP showed better accuracy in the diagnosis of HCC when compared to the single use of these biomarkers (48).

Glipican-3 (GPC3). GPC3 is a member of the proteoglycan heparan sulfate family, comprised of 6 subtypes of glypicans (GPC1-6), which have several functions, the main one being to regulate Wnt, Hedgehog, bone morphogenic protein (BMP) and fibroblastic growth factor signaling (49). GPC3 is present in different stages and different tissues during embryonic development, which indicates its involvement in morphogenesis (50). In adult liver, no GPC3 expression is detected (51) while microarray analysis of tissue samples revealed increased GPC3 expression in $63.6 \%$ of HCC patients (52). The mechanisms involving GPC3 in the development of HCC have been described by Zhou et al., and include stimulation of Wnt signaling, interaction with growth factors, stimulation of macrophage recruitment and promotion of epithelium-mesenchymal transition (EMT) (53). The literature indicates GPC3 as a highly specific biomarker, and the combination of markers has shown improved sensitivity in the distinction between HCC and non-malignant hepatocellular lesions, as Enan et al. pointed out by combining GPC3 with CD34 and obtaining 82\% sensitivity (54). Nault et al. have studied the serum levels of GPC3 in patients with hepatic cirrhosis, obtaining significantly higher values in patients with advanced HCC when compared to patients without HCC or in patients with early stage disease (55). 
Alpha-1-fucosidase (AFU). AFU is a lysosomal enzyme that can be detected in the serum of healthy patients, but its activity is increased in patients with $\mathrm{HCC}$, cirrhosis and chronic hepatitis (56). In the study of Fawzy et al., the AFU values of 80 patients ( 40 with $\mathrm{HCC}$ and 40 with chronic liver diseases) and 40 healthy individuals were measured and compared (57). The results showed significantly higher serum AFU values in the HCC group when compared to the other two groups $(p<0.001)$, and for AFU cut-off value of 2.3005 micromol $\left(1^{-1}\right)\left(\mathrm{min}^{-1}\right)$ the sensitivity and specificity delivered were $90 \%$ and $97.5 \%$, respectively (57). The study also found a decrease in AFU values in patients who underwent local therapies for HCC [radiofrequency ablation (RFA) or transarterial chemoembolization (TACE)] (57). Thus, AFU has shown promise as a biomarker for the diagnosis of HCC and for the follow-up of therapeutic results (57).

Squamous cell carcinoma antigen (SCCA). SCCA is a serine protease inhibitor, physiologically found in squamous epithelium, but also expressed in epithelial cell neoplasms (58). Caterina et al., have studied the serum levels of the immunocomplex SCCA with IgM (SCCA-IgM) in patients with $\mathrm{HCC}$ and found sensitivity and specificity values of $89 \%$ and $50 \%$, respectively, regarding the diagnosis of HCC (59). In the meta-analysis of Liu et al., both SCCA and SCCA-IgM showed moderate diagnostic accuracy in HCC, but combining SCCA-IgM with AFP there was an increase in diagnostic accuracy and early detection of HCC (60).

Golgi protein-73 (GP73). The GP73, is a transmembrane protein of the Golgi apparatus expressed in the normal liver, is mostly secreted by cells of the biliary epithelium and has insignificant expression in the hepatocytes (61). It was isolated for the first time in 2000, when its expression was observed in liver tissue cells of patients with cirrhosis and chronic hepatitis but not in normal liver cells in in vitro experiments (61). Later, it was demonstrated that serum levels of GP73 are significantly higher in HCC patients compared to healthy individuals (62). In the study of Jiao et al., 180 patients with HCC, 61 with cirrhosis of the liver, 99 with chronic hepatitis, and 103 healthy individuals, were submitted to blood sampling (63). It was shown, that the serum levels of GP73 were significantly higher in patients with HCC when compared to those in the other three groups (63). From the analysis of clinical and pathological variables, the presence of lymphatic metastasis was associated with high GP73 levels in patients with lymph node metastasis (63). As for HCC diagnosis, GP73 showed, for the optimal cut-off value of $117.53 \mathrm{ng} / \mathrm{ml}$, a sensitivity of $78.3 \%$ and a specificity of $85.4 \%$. However, AFP showed sensitivity and specificity values of $51.1 \%$ and $99 \%$, respectively, for the optimal cut-off value of $176.91 \mathrm{ng} / \mathrm{ml}$, which shows that GP73 is more efficient in the early detection of HCC compared to AFP (63). The combination of GP73 with AFP presented the largest AUC, and obtained better sensitivity and specificity values (63).

\section{Phase 3}

Osteopontine $(O P N)$. OPN is a multifunctional protein that is involved in several pathological processes such as inflammation and carcinogenesis in several tissues (64). In HCC, the plasma levels of OPN have been considered as a potential biomarker (65). Zhu et al. have conducted a study with 322 patients (105 with chronic hepatitis, 116 with cirrhosis and 101 with hepatocellular carcinoma) (66). Serum samples from patients were obtained before any invasive procedure, such as surgery or biopsy, and before any nonsurgical oncologic treatment, such as chemotherapy or radiotherapy. The results showed significantly higher OPN values in patients with HCC (median $39.84 \mathrm{ng} / \mathrm{ml}$, $\mathrm{IQR}=15.55-91.81$ ) when compared with the values of patients with chronic hepatitis (median $10.18 \mathrm{ng} / \mathrm{ml}$ ) and liver cirrhosis $(10.93 \mathrm{ng} / \mathrm{ml})$ (66). In the diagnosis of HCC in the risk group (patients with chronic hepatitis and liver cirrhosis) and AFP-negative individuals (with cut-off value of $20 \mathrm{ng} / \mathrm{ml}$ ), OPN showed sensitivity of $78.26 \%$ and specificity of $80.45 \%$ (66). In the diagnosis of HCC, OPN reached higher values of AUC when compared to AFP [AUC: $0.851 \quad(95 \% \mathrm{CI}=0.807-0.888)$ vs. AUC: 0.68 (95\% CI $=0.629-0.734)]$, and in the optimal cut off value of OPN $(14.64 \mathrm{ng} / \mathrm{ml})$ the sensitivity was $79.21 \%$ and the specificity $79.24 \%$ (66). When AFP and OPN were combined, the value of AUC increased to $0.876(p<0.0001)$, higher than AFP and OPN alone, and reached $88.12 \%$ and $74.21 \%$ of sensitivity and specificity, respectively (66). Regarding the early detection of HCC, patients with tumors smaller than $2 \mathrm{~cm}$ presented significantly higher OPN values (mean $=29.67 \mathrm{ng} / \mathrm{ml}, \mathrm{IQR}=14.69-47.97)$ when compared to those with chronic hepatitis $(p<0.0001)$ and those with hepatic cirrhosis $(\mathrm{p}=0.0029)$, and the performance of OPN was higher than AFP in these patients (66). These results suggest that OPN is promising in the early detection of $\mathrm{HCC}$, although the number of patients in this group was low and other studies need to confirm it (66).

Midkine (MDK). MDK is a growth factor that binds to heparin which is encoded by the MDK gene on chromosome 11. It plays a key role in carcinogenic activities such as proliferation, migration and angiogenesis, its serum values are increased in most cases of HCC, and can play a key role in AFP-negative patients and patients with tumors in the early stages $(67,68)$. In the most recent meta-analysis of Zhang et al., 10 studies were selected representing a total of 1730 individuals (753 with HCC and 977 without HCC); the sensitivity and specificity of MDK for the diagnosis of $\mathrm{HCC}$ was $86 \% \quad(95 \% \mathrm{CI}=83.3-88.4 \%)$ and $75.4 \%$ 
(95\% CI=72.6-78.1\%), respectively (69). This meta-analysis, however, presented significant heterogeneity as well as limitations that may have affected the results. In a study by Zekri et al., single or combined biomarkers were compared; for optimal MDK cut-off values, sensitivity was $88.5 \%$ and specificity $80.6 \%(p<0.001)$, and their serum levels were significantly higher in HCC patients (70). Vongsuvanh et al. investigated the role of MDK in AFP-negative patients with HCC $(\mathrm{AFP}<20 \mathrm{ng} / \mathrm{ml})$, and found that in $59.18 \%$ of these patients the levels of MDK (MDK >0.44 ng/ml) were high, which indicated the possible importance of MDK complementary to AFP (68). It is, therefore, necessary to develop more rigorous studies with larger samples to obtain future evidence on the role of MDK in the diagnosis of HCC (70).

Des-carboxyprothrombin (DCP). DCP, also known as vitamin $\mathrm{K}$-induced protein, is a protein produced by hepatocytes in situations of vitamin K deficiency (71). Multiple mechanisms raise the levels of CPD in patients with HCC, including genetic alterations in the hepatocytes, changes in their cytoskeleton or unregulated entry of vitamin $\mathrm{K}$ (71). In the systematic review of Ji De et al., the results showed 66\% grouped sensitivity and $88 \%$ grouped specificity of serum DCP in the diagnosis of HCC (72). The study of Lok. et al. who compared the accuracy of AFP and DCP in the early diagnosis of HCC, showed that these biomarkers were complementary, achieving better sensitivity results when combined (73). However, further studies are needed to determine whether this combination of biomarkers improves early detection of HCC.

GALAD score (Gender, Age, AFP-L3, DCP). The GALAD Score is a tool based on parameters such as gender, age and the serological biomarkers AFP, DCP and AFP-L3 (74). Yang et al. have compared GALAD Score and liver ultrasonography (74). They obtained $91 \%$ sensitivity and $85 \%$ specificity in HCC detection (74). When the analysis was restricted to initial stage HCC patients, the AUC of the GALAD Score remained high and was higher than the ultrasound (0.92 vs. 0.82, $p<0.001)$ (74). Thus, despite the limitations of the study, the GALAD score showed potential as a complementary parameter compared to ultrasound, being particularly important in the detection of HCC in patients with high liver dysfunction and obesity, conditions that increase the risk of obtaining false-negative abdominal ultrasound (74). Berhane et al. compared the GALAD Score with the AFP, AFP-L3 and DCP single biomarkers and showed $91.6 \%$ sensitivity and $89.7 \%$ specificity for the GALAD Score in HCC diagnosis, significantly higher than the single biomarkers, indicating the GALAD Score as a tool capable of detecting tumors in which curative treatments are more applicable (75).

\section{Phase 4}

To date, there are no phase 4 biomarkers that have completed the tests for early diagnosis of HCC. Progress is hampered by the lack of suitable phase 3 samples for validation (76).

\section{Phase 5}

Alpha-fetoprotein (AFP). Although not all HCCs secrete AFP and other liver diseases can show increased levels of this marker, AFP is the most commonly used biomarker in HCC surveillance (77). Tzartzeva et al. have analyzed studies on HCC surveillance performance in patients with hepatic cirrhosis and obtained results indicating best sensitivity in early stage HCC detection when AFP was associated with ultrasound (mean sensitivity of 97\%) (78). AFP can correlate with alanine aminotransferase (ALT) and aspartate aminotransferase (AST), especially in patients with hepatitis $\mathrm{C}$, which implies reduced specificity of this biomarker (79). However, Liu et al. have studied whether the relationship between AFP, AST and ALT could result in an index that would be useful in HCC and, despite the limitations of the research, this relationship was able to provide information regarding the diagnosis, therapeutic outcome and prognosis of HCC (80). AFP cut-off values vary according to guidelines around the world (81). The meta-analysis of Zhang et al. examined these values and concluded that the AFP cut off of $400 \mathrm{ng} / \mathrm{ml}$ shows the best accuracy in HCC diagnosis, while the cut off of $20 \mathrm{ng} / \mathrm{ml}$ can be used for follow-up after treatment, as it presents high sensitivity (81). However, future studies should focus on the dynamics of changing AFP values as HCC progresses. The potential of AFP values in predicting transplant outcomes has been studied by Toso et al. (82). They have shown that AFP values can be used as a predictor of post-transplant global survival and can be included in the selection criteria along with morphological variables (size and number) (82). Duvoux et al. have proposed an HCC recurrence prediction model that incorporates AFP values and compared its accuracy with the Milan criterion. Establishing the relationship between AFP levels and tumor behavior, such as presence of vascular invasion, and consequently with prognosis, they pointed out that the adoption of AFP, a simple and reliable tool, to the selection criteria of patients for transplantation can refine this choice (83). Metha et al. have demonstrated that the serum levels of AFP are an important biomarker in predicting post-transplant recurrence (84). In patients with preoperative serum AFP $>1000 \mathrm{ng} / \mathrm{ml}$, the disease-free survival was $53 \%$, while in patients with AFP $<1000 \mathrm{ng} / \mathrm{ml}$ it was $80 \%$ (84). Halazun et al. have published a model that incorporates the AFP response concept, which is the difference between the highest and final value of serum AFP before transplantation while in the waiting list, to the criteria for patient selection. AFP response to treatment is an important tool that can improve patient selection and outcomes after transplantation (85). 


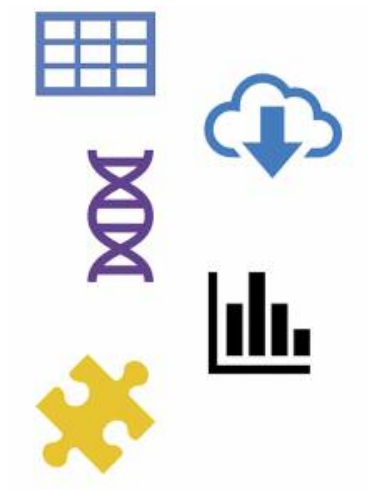

Databases/Raw data

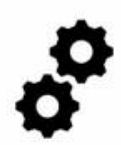

III)
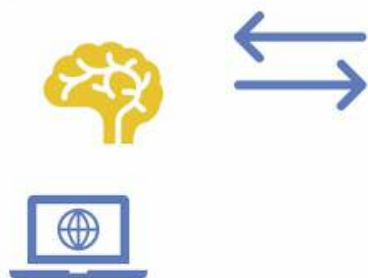

Artificial Intelligence
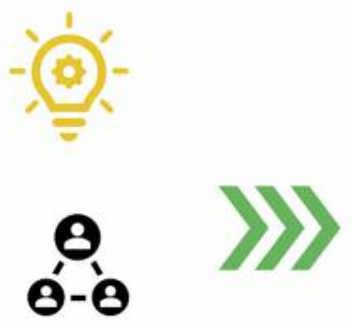

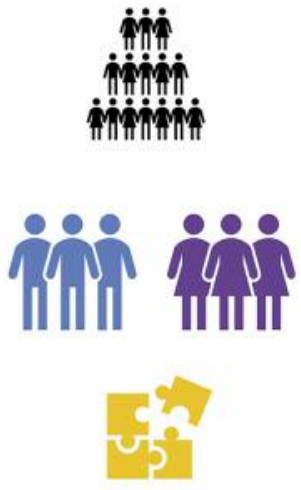

Group selections

Figure 1. "Machine learning" application algorithm.

\section{Future Directions}

Artificial intelligence (AI) can be defined as the study of algorithms that give machines the ability to reason and perform cognitive functions such as problem solving, object and word recognition, and decision making (86). One of the subfields of AI is machine learning (ML). ML allows machines to learn from the data and make predictions through pattern recognition (87). In the case of supervised ML, data are analysed using an ML algorithm with reinforcement learning to potentially identify clinically applicable patterns, and from a set of predictors (such as the clinical characteristics of a patient) to be able to predict outcomes (such as HCC recurrence) (87).

ML algorithms can be static or incorporate new information that allows constant improvement of the forecasting tool, allowing the algorithm to perfect itself (87). Thus, ML can be used to build a forecasting tool for a given population of HCC patients to identify those most likely to benefit from the various treatments and determine the most important variables to distinguish these patients, as presented in Figure 1. ML considers all the variables available in a given database as "Big-data" and incorporates the interrelationships between them in the outcome prediction tool (87).

\section{Conclusion}

New biomarkers predictors of tumor biology have been investigated to adequately select patients for each treatment offered. To date, the response to initial treatment and the biological behavior of the tumor are effectively used in clinical practice in HCC patients. Artificial intelligence technologies, capable of taking into account clinical-laboratory and biological tumor data, need to be implemented, so that information from the so-called Big-data, is correctly interpreted for anticipating the chances of tumor recurrence in HCC. Several molecules related to HCC can contribute to the complete understanding of the disease, and indirectly estimate the response to the indicated treatment.

\section{Conflicts of Interest}

The Authors have no conflicts of interest to declare regarding this study.

\section{Authors' Contributions}

This manuscript was written under the role assignment specified below. PA as corresponding author, and RF, were primarily in charge of manuscript drafting and contributed equally to it. VM, MAR, FGF conducted literature review and participated in study design. RMMV, FDST, LAS supervised drafting of the manuscript and gave final approval of the version to be published. All Authors read and approved the final manuscript.

\section{References}

1 Ferlay J, Soerjomataram I, Dikshit R, Eser S, Mathers C, Rebelo M, Parkin DM, Forman D and Bray F: Cancer incidence and mortality worldwide: Sources, methods and major patterns in GLOBOCAN 2012. Int J Cancer 136(5): E359-86, 2015. PMID: 25220842. DOI: $10.1002 / \mathrm{ijc} .29210$

2 Setshedi M, Andersson M, Kgatle MM and Roberts L: Molecular and cellular oncogenic mechanisms in hepatocellular carcinoma. S Afr Med J 108(8b): 41-46, 2018. PMID: 30182912. DOI: $10.7196 /$ SAMJ.2018.v108i8b.13500

3 White DL, Thrift AP, Kanwal F, Davila J and El-Serag HB: Incidence of hepatocellular carcinoma in all 50 United States, from 2000 through 2012. Gastroenterology 152(4): 812-820.e5, 2017. PMID: 27889576. DOI: 10.1053/j.gastro.2016.11.020 
4 Harris PS, Hansen RM, Gray ME, Massoud OI, McGuire BM and Shoreibah MG: Hepatocellular carcinoma surveillance: An evidence-based approach. World J Gastroenterol 25(13): 15501559, 2019. PMID: 30983815. DOI: 10.3748/wjg.v25.i13.1550

5 Bruix $J$ and Sherman M: Management of hepatocellular carcinoma: An update. Hepatology 53(3): 1020-1022, 2011. PMID: 21374666. DOI: 10.1002/hep.24199

6 Marrero JA, Kulik LM, Sirlin CB, Zhu AX, Finn RS, Abecassis MM, Roberts LR and Heimbach JK: Diagnosis, staging, and management of hepatocellular carcinoma: 2018 Practice Guidance by the American Association for the Study of Liver Diseases. Hepatology 68(2): 723-750, 2018. PMID: 29624699. DOI: $10.1002 /$ hep. 29913

7 Llovet JM, Fuster J and Bruix J: The Barcelona approach: Diagnosis, staging, and treatment of hepatocellular carcinoma. Liver Transplantation 10(S2): S115-20, 2004. PMID: 14762851. DOI: $10.1002 / 1 \mathrm{t} .20034$

8 Pinna AD, Yang T, Mazzaferro V, de Carlis L, Zhou J, Roayaie S, Shen F, Sposito C, Cescon M, Di-Sandro S, Yi-Feng H, Johnson P and Cucchetti A: Liver transplantation and hepatic resection can achieve cure for hepatocellular carcinoma. Ann Surg 268(5): 868-875, 2018. PMID: 30080736. DOI: 10.1097/SLA.0000000000002889

9 Sarveazad A, Agah S, Babahajian A, Amini N and Bahardoust M: Predictors of 5 year survival rate in hepatocellular carcinoma patients. J Res Med Sci 24(1): 86, 2019. PMID: 31741658. DOI: 10.4103/jrms.JRMS_1017_18

10 Pepe MS, Etzioni R, Feng Z, Potter JD, Thompson ML, Thornquist $\mathrm{M}$, Winget $\mathrm{M}$ and Yasui $\mathrm{Y}$ : Phases of biomarker development for early detection of cancer. J Natl Cancer Inst 93(14): 1054-1061, 2001. PMID: 11459866. DOI: 10.1093/jnci/ 93.14.1054

11 Singal AG, Pillai A and Tiro J: Early detection, curative treatment, and survival rates for hepatocellular carcinoma surveillance in patients with cirrhosis: A meta-analysis. PLoS Med 11(4): e1001624, 2014. PMID: 24691105. DOI: 10.1371/journal.pmed.1001624.

12 Singal AG, Nehra M, Adams-Huet B, Yopp AC, Tiro JA, Marrero JA, Lok AS and Lee WM: Detection of hepatocellular carcinoma at advanced stages among patients in the HALT-C trial: Where did surveillance fail? Am J Gastroenterol 108(3): 425-432, 2013. PMID: 23337478. DOI: 10.1038/ajg.2012.449

13 Singal A, Volk ML, Waljee A, Salgia R, Higgins P, Rogers MAM and Marrero JA: Meta-analysis: Surveillance with ultrasound for early-stage hepatocellular carcinoma in patients with cirrhosis. Aliment Pharmacol Ther 30(1): 37-47, 2009. PMID: 19392863. DOI: 10.1111/j.1365-2036.2009.04014.x

14 Chagas AL, Mattos AA, Carrilho FJ, Bittencourt PL; Members of the Panel of the 2nd Consensus of the Brazilian Society of Hepatology on the Diagnosis and Management of Hepatocellular Carcinoma, Vezozzo DCP, Horvat N, Rocha MS, Alves VAF, Coral GP, Alvares-DA-Silva MR, Barros FMDR, Menezes MR, Monsignore LM, Coelho FF, Silva RFD, Silva RCMA, Boin IFSF, D Albuquerque LAC, Garcia JHP, Felga GEG, Moreira AM, Braghiroli MIFM, Hoff PMG, Mello VB, Dottori MF, Branco TP, Schiavon LL and Costa TFA: Brazilian society of hepatology updated recommendations for diagnosis and treatment of hepatocellular carcinoma. Arq Gastroenterol 57(suppl 1): 1-20, 2020. PMID: 32294682. DOI: 10.1590/ S0004-2803.202000000-20
15 Paranaguá-Vezozzo DC, Ono SK, Alvarado-Mora MV, Farias AQ, Cunha-Silva M, França JID, Alves VAF, Sherman M and Carrilho FJ: Epidemiology of HCC in Brazil: Incidence and risk factors in a ten-year cohort. Ann Hepatol 13(4): 386-393, 2014. PMID: 24927609.

16 Hass HG, Jobst J, Scheurlen M, Vogel U and Nehls O: Gene expression analysis for evaluation of potential biomarkers in hepatocellular carcinoma. Anticancer Res 35(4): 2021-2028, 2015. PMID: 25862856.

17 Strimbu K and Tavel JA: What are biomarkers? Curr Opin HIV AIDS 5(6): 463-466, 2010. PMID: 20978388. DOI: 10.1097/COH.0b013e32833ed177

18 Sia D, Villanueva A, Friedman SL and Llovet JM: Liver cancer cell of origin, molecular class, and effects on patient prognosis. Gastroenterology 152(4): 745-761, 2017. PMID: 28043904. DOI: $10.1053 /$ j.gastro.2016.11.048

19 Borges KA, Dai J, Parikh ND, Schwartz M, Nguyen MH, Roberts LR, Befeler AS, Srivastava S, Rinaudo JA, Feng Z, Marrero JA and Reddy KR: Rationale and design of the hepatocellular carcinoma early detection strategy study: A multicenter longitudinal initiative of the National Cancer Institute's Early Detection Research Network. Contemp Clin Trials 76: 4954, 2019. PMID: 30439517. DOI: 10.1016/j.cct.2018.11.008

20 Sartorius K, Sartorius B, Winkler C, Chuturgoon A and Makarova J: The biological and diagnostic role of miRNA's in hepatocellular carcinoma. Front Biosci (Landmark Ed) 23(9): 1701-1720, 2018. PMID: 29293458. DOI: 10.2741/4668

21 Huang JT, Liu SM, Ma H, Yang Y, Zhang X, Sun H, Zhang X, $\mathrm{Xu} \mathrm{J}$ and Wang J: Systematic review and meta-analysis: Circulating miRNAs for diagnosis of hepatocellular carcinoma. J Cell Physiol 231(2): 328-335, 2016. PMID: 26291451. DOI: $10.1002 /$ jcp. 25135

22 Huang YH, Liang KH, Chien RN, Hu TH, Lin KH, Hsu CW, Lin CL, Pan TL, Ke PY and Yeh CT: A circulating MicroRNA signature capable of assessing the risk of hepatocellular carcinoma in cirrhotic patients. Sci Rep 7(1): 523, 2017. PMID: 28364124. DOI: 10.1038/s41598-017-00631-9

$23 \mathrm{Wu}$ J, Wu Y, Luo Y, Li X, Lin N, Yang X, Lin Y and Chen M: Circulating miRNA-199a and miRNA-122 levels as potential diagnostic and prognostic biomarkers for hepatocellular carcinoma. Ann Clin Lab Sci 50(2): 219-227, 2020. PMID: 32366560 .

24 Sugimoto M, Wong DT, Hirayama A, Soga T and Tomita M: Capillary electrophoresis mass spectrometry-based saliva metabolomics identified oral, breast and pancreatic cancerspecific profiles. Metabolomics 6(1): 78-95, 2010. PMID: 20300169. DOI: 10.1007/s11306-009-0178-y

25 Matteis S de, Ragusa A, Marisi G, Domenico S de, Gardini AC, Bonafè $M$ and Giudetti AM: Aberrant metabolism in hepatocellular carcinoma provides diagnostic and therapeutic opportunities. Oxid Med Cell Longev 2018: 7512159, 2018. PMID: 30524660. DOI: 10.1155/2018/7512159

26 Li ZF, Wang J, Huang C, Zhang S, Yang J, Jiang A, Zhou R and Pan D: Gas chromatography/time-of-flight mass spectrometry-based metabonomics of hepatocarcinoma in rats with lung metastasis: elucidation of the metabolic characteristics of hepatocarcinoma at formation and metastasis. Rapid Commun Mass Spec 24(18): 27652775, 2010. PMID: 20814984. DOI: 10.1002/rcm.4703

27 Wang B, Chen D, Chen Y, Hu Z, Cao M, Xie Q, Chen Y, Xu J, Zheng $\mathrm{S}$ and $\mathrm{Li} \mathrm{L}$ : Metabonomic profiles discriminate 
hepatocellular carcinoma from liver cirrhosis by ultraperformance liquid chromatography-mass spectrometry. J Proteome Res 11(2): 1217-1227, 2012. PMID: 22200553. DOI: $10.1021 /$ pr2009252

28 Luo P, Yin P, Hua R, Tan Y, Li Z, Qiu G, Yin Z, Xie X, Wang X, Chen W, Zhou L, Wang X, Li Y, Chen H, Gao L, Lu X, Wu T, Wang H, Niu J and Xu G: A Large-scale, multicenter serum metabolite biomarker identification study for the early detection of hepatocellular carcinoma. Hepatology 67(2): 662-675, 2018. PMID: 28960374. DOI: 10.1002/hep.29561

29 Feng JT, Shang S and Beretta L: Proteomics for the early detection and treatment of hepatocellular carcinoma. Oncogene 25(27): 3810-3817, 2006. PMID: 16799622. DOI: 10.1038/sj.onc. 1209551

30 Wang M, Devarajan K, Singal AG, Marrero JA, Dai J, Feng Z, Rinaudo JA, Srivastava S, Evans A, Hann HW, Lai Y, Yang H, Block TM and Mehta A: The Doylestown Algorithm: A test to improve the performance of AFP in the detection of hepatocellular carcinoma. Cancer Prevent Res 9(2): 172-179, 2016. PMID: 26712941. DOI: 10.1158/1940-6207.CAPR-15-0186

31 Wang M, Sanda M, Comunale MA, Herrera H, Swindell C, Kono Y, Singal AG, Marrero J, Block T, Goldman R and Mehta A: Changes in the glycosylation of kininogen and the development of a kininogen-based algorithm for the early detection of HCC. Cancer Epidemiol Biomarkers Prevent 26(5): 795-803, 2017. PMID: 28223431. DOI: 10.1158/1055-9965.EPI-16-0974

32 Gao Q, Zhu H, Dong L, Shi W, Chen R, Song Z, Huang C, Li J, Dong X, Zhou Y, Liu Q, Ma L, Wang X, Zhou J, Liu Y, Boja E, Robles AI, Ma W, Wang P, Li Y, Ding L, Wen B, Zhang B, Rodriguez $\mathrm{H}$, Gao D, Zhou $\mathrm{H}$ and Fan J: Integrated proteogenomic characterization of HBV-related hepatocellular carcinoma. Cell 179(5): 1240, 2019. PMID: 31730861. DOI: 10.1016/j.cell.2019.10.038

33 Gillies RJ, Kinahan PE and Hricak H: Radiomics: Images are more than pictures, they are data. Radiology 278(2): 563-577, 2016. PMID: 26579733. DOI: 10.1148/radiol.2015151169

34 Hesketh RL, Zhu AX and Oklu R: Radiomics and circulating tumor cells: Personalized care in hepatocellular carcinoma? Diagn Intervent Radiol 21(1): 78-84, 2015. PMID: 25430530. DOI: $10.5152 /$ dir.2014.14237

35 Zhou Y, He L, Huang Y, Chen S, Wu P, Ye W, Liu Z and Liang $\mathrm{C}$ : CT-based radiomics signature: a potential biomarker for preoperative prediction of early recurrence in hepatocellular carcinoma. Abdom Radiol 42(6): 1695-1704, 2017. PMID: 28180924. DOI: $10.1007 / \mathrm{s} 00261-017-1072-0$

36 Zheng J, Chakraborty J, Chapman WC, Gerst S, Gonen M, Pak LM, Jarnagin WR, DeMatteo RP, Do RKG and Simpson AL: Preoperative prediction of microvascular invasion in hepatocellular carcinoma using quantitative image analysis. J Am Coll Surg 225(6): 778-788.e1, 2017. PMID: 28941728. DOI: $10.1016 /$ j.jamcollsurg.2017.09.003

37 Ma M, Feng Z, Peng T, Yan H, Rong P and Jumbe MM: Radiomics and its advances in hepatocellular carcinoma. Zhong Nan Da Xue Xue Bao Yi Xue Ban 44(3): 225-232, 2019. PMID: 30971513. DOI: 10.11817/j.issn.1672-7347.2019.03.001

38 Bao J, Yu Y, Chen J, He Y, Chen X, Ren Z, Xue C, Liu L, Hu Q, Li J, Cui G and Sun R: MiR-126 negatively regulates PLK-4 to impact the development of hepatocellular carcinoma via ATR/CHEK1 pathway. Cell Death Dis 9(10): 1045, 2018. PMID: 30315225. DOI: $10.1038 / \mathrm{s} 41419-018-1020-0$
39 Colwill K, Gräslund S, Persson H, Jarvik NE, Wyrzucki A and Wojcik J: A roadmap to generate renewable protein binders to the human proteome. Nature 8(7): 551-561, 2011. PMID: 21572409. DOI: $10.1038 /$ nmeth.1607

40 Liao Z, Zhang H, Fan P, Huang Q, Dong K, Qi Y, Song J, Chen L, Liang H, Chen X, Zhang Z, Zhang B. High PLK4 expression promotes tumor progression and induces epithelial-mesenchymal transition by regulating the $\mathrm{Wnt} / \beta$-catenin signaling pathway in colorectal cancer. Int J Oncol 54(2): 479-490, 2019. PMID: 30570110. DOI: $10.3892 /$ ijo.2018.4659

41 Korzeniewski N, Hohenfellner M and Duensing S: CAND1 promotes PLK4-mediated centriole overduplication and is frequently disrupted in prostate cancer. Neoplasia 14(9): 799806, 2012. PMID: 23019411. DOI: 10.1593/neo.12580

42 Coelho PA, Bury L, Shahbazi MN, Liakath-Ali K, Tate PH, Wormald S, Hindley CJ, Huch M, Archer J, Skarnes WC, Zernicka-Goetz M and Glover DM: Over-expression of Plk4 induces centrosome amplification, loss of primary cilia and associated tissue hyperplasia in the mouse. Open Biol 5(12): 150209, 2015. PMID: 26701933. DOI: 10.1098/rsob.150209

43 Levine MS, Bakker B, Boeckx B, Moyett J, Lu J, Vitre B, Spierings DC, Lansdorp PM, Cleveland DW, Lambrechts D, Foijer $\mathrm{F}$ and Holland AJ: Centrosome amplification is sufficient to promote spontaneous tumorigenesis in mammals. Dev Cell 40(3): 313-322.e5, 2017. PMID: 28132847. DOI: 10.1016/j.devcel.2016.12.022

44 Khien VV, Mao HV, Chinh TT, Ha PT, Bang MH, Lac BV, Hop TV, Tuan NA, Don LV, Taketa K and Satomura S: Clinical evaluation of lentil lectin-reactive alpha-fetoprotein-13 in histology-proven hepatocellular carcinoma. Int J Biol Markers 16(2): 105-111, 2001. PMID: 11471892.

45 Toyoda H, Kumada T, Tada T, Kaneoka Y, Maeda A, Kanke F and Satomura S: Clinical utility of highly sensitive Lens culinaris agglutinin-reactive alpha-fetoprotein in hepatocellular carcinoma patients with alpha-fetoprotein $<20 \mathrm{ng} / \mathrm{mL}$. Cancer Sci 102(5): 1025-1031, 2011. PMID: 21244578. DOI: 10.1111/j.1349-7006.2011.01875.x

46 Lozada ME, Chaiteerakij R and Roberts LR: Screening for hepatocellular carcinoma and cholangiocarcinoma: Can biomarkers replace imaging? Curr Hep Rep 14(2): 128-138, 2015. PMID: 26328266. DOI: 10.1007/s11901-015-0261-y

47 Shen Q, Fan J, Yang XR, Tan Y, Zhao W, Xu Y, Wang N, Niu Y, Wu Z, Zhou J, Qiu SJ, Shi YH, Yu B, Tang N, Chu W, Wang M, Wu J, Zhang Z, Yang S, Gu J, Wang H and Qin W: Serum DKK1 as a protein biomarker for the diagnosis of hepatocellular carcinoma: A large-scale, multicentre study. Lancet Oncol 13(8): $817-826$, 2012. PMID: 22738799. DOI: $10.1016 / \mathrm{S} 1470-$ 2045(12)70233-4

48 Li Z, Mou L, Gao H, Zeng Y, Tang X, Deng X, Pu Z, Ni Y and Zhan Y: Diagnostic accuracy of serum dickkopf-1 protein in diagnosis hepatocellular carcinoma: An updated meta-analysis. Medicine (Baltimore) 98(32): e16725, 2019. PMID: 31393380. DOI: 10.1097/MD.0000000000016725

49 Filmus J, Capurro M and Rast J: Glypicans. Genome Biol 9(5): 224, 2008. PMID: 18505598. DOI: 10.1186/gb-2008-9-5-224

50 Iglesias BV, Centeno G, Pascuccelli H, Ward F, Peters MG, Filmus J, Puricelli L and Joffé EBK: Expression pattern of glypican-3 (GPC3) during human embryonic and fetal development. Histol Histopathol 23(11): 1333-1340, 2008. PMID: 18785116. DOI: 10.14670/HH-23.1333 
51 Haruyama $\mathrm{Y}$ and Kataoka H: Glypican-3 is a prognostic factor and an immunotherapeutic target in hepatocellular carcinoma. World J Gastroenterol 22(11): 275-283, 2016. PMID: 26755876. DOI: $10.3748 /$ wjg.v22.i1 .275

52 Baumhoer D, Tornillo L, Stadlmann S, Roncalli M, Diamantis EK and Terracciano LM: Glypican 3 expression in human nonneoplastic, preneoplastic, and neoplastic tissues: A tissue microarray analysis of 4,387 tissue samples. Am J Clin Pathol 129(6): 899-906, 2008. PMID: 18480006. DOI: 10.1309/HCQWPWD50XHD2DW6

53 Zhou F, Shang W, Yu X and Tian J: Glypican-3: A promising biomarker for hepatocellular carcinoma diagnosis and treatment. Med Res Rev 38(2): 741-767, 2018. PMID: 28621802. DOI: $10.1002 /$ med.21455

54 Enan ET, El-Hawary AK, El-Tantawy DAEA, Abu-Hashim MM and Helal NM: Diagnostic role of glypican 3 and CD34 for differentiating hepatocellular carcinoma from nonmalignant hepatocellular lesions. Ann Diagn Pathol 17(6): 490-493, 2013. PMID: 24012547. DOI: 10.1016/j.anndiagpath.2013.08.001

55 Nault JC, Guyot E, Laguillier C, Chevret S, Ganne-Carrie N, N'Kontchou G, Beaugrand M, Seror O, Trinchet JC, Coelho J, Lasalle P, Charnaux N, Delehedde M, Sutton A and Nahon P: Serum proteoglycans as prognostic biomarkers of hepatocellular carcinoma in patients with alcoholic cirrhosis. Cancer Epidemiol Biomarkers Prevent 22(8): 1343-1352, 2013. PMID: 23780836. DOI: 10.1158/1055-9965.EPI-13-0179

56 Giardina MG, Matarazzo M, Varriale A, Morante R, Napoli A and Martino R: Serum alpha-L-fucosidase. A useful marker in the diagnosis of hepatocellular carcinoma. Cancer 70(5): 10441048, 1992. PMID: 1381268. DOI: 10.1002/10970142(19920901)70:5<1044::aid-cncr2820700506>3.0.co;2-u

57 Fawzy Montaser M, Amin Sakr M and Omar Khalifa M: Alpha1-fucosidase as a tumour marker of hepatocellular carcinoma. Arab J Gastroenterol 13(1): 9-13, 2012. PMID: 22560818. DOI: 10.1016/j.ajg.2012.03.006

58 Kato H: Expression and function of squamous cell carcinoma antigen. Anticancer 16(4B): 2149-2153, 1996. PMID: 8694535.

59 Pozzan C, Cardin R, Piciocchi M, Cazzagon N, Maddalo G, Vanin V, Giacomin A, Pontisso P, Cillo U and Farinati F: Diagnostic and prognostic role of SCCA-IgM serum levels in hepatocellular carcinoma (HCC). J Gastroenterol Hepatol 29(8): 1637-1644, 2014. PMID: 24635038. DOI: 10.1111/jgh.12576

60 Liu CH, Gil-Gómez A, Ampuero J and Romero-Gómez M: Diagnostic accuracy of SCCA and SCCA-IgM for hepatocellular carcinoma: A meta-analysis. Liver Int 38(10): 1820-1831, 2018. PMID: 29704434. DOI: 10.1111/liv.13867

61 Kladney RD, Bulla GA, Guo L, Mason AL, Tollefson AE, Simon DJ, Koutoubi Z and Fimmel CJ: GP73, a novel Golgilocalized protein upregulated by viral infection. Gene 249(1-2): 53-65, 2000. PMID: 10831838. DOI: 10.1016/s03781119(00)00136-0

62 Tian L, Wang Y, Xu D, Gui J, Jia X, Tong H, Wen X, Dong Z and Tian Y: Serological AFP/Golgi protein 73 could be a new diagnostic parameter of hepatic diseases. International J Cancer 129(8): 1923-1931, 2011. PMID: 21140449. DOI: 10.1002/ijc. 25838

63 Jiao C, Cui L, Piao J, Qi Y and Yu Z: Clinical significance and expression of serum Golgi protein 73 in primary hepatocellular carcinoma. J Cancer Res Ther 14(6): 1239-1244, 2018. PMID: 30488837. DOI: 10.4103/0973-1482.199784
64 Wen Y, Jeong S, Xia Q and Kong X: Role of osteopontin in liver diseases. Int J Biol Sci 12(9): 1121-1128, 2016. PMID: 27570486. DOI: $10.7150 /$ ijbs.16445

65 Shang S, Plymoth A, Ge S, Feng Z, Rosen HR, Sangrajrang S, Hainaut $\mathrm{P}$, Marrero JA and Beretta L: Identification of osteopontin as a novel marker for early hepatocellular carcinoma. Hepatology 55(2): 483-490, 2012. PMID: 21953299. DOI: $10.1002 /$ hep. 24703

66 Zhu M, Zheng J, Wu F, Kang B, Liang J, Heskia F, Zhang X and Shan Y: OPN is a promising serological biomarker for hepatocellular carcinoma diagnosis. J Med Virol, 2020. PMID: 32043608. DOI: 10.1002/jmv.25704

67 Yan Q, Huang HL, Yao X, Li J, Li LQ, Zhong J, Min LS, Dai LC and Zheng SS: Novel functional proteins interact with midkine in hepatic cancer cells. Hepatobiliary Pancreat Dis Int 11(3): 272-277, 2012. PMID: 22672821. DOI: 10.1016/s14993872(12)60160-x

68 Vongsuvanh R, van Poorten D der, Iseli T, Strasser SI, McCaughan GW and George J: Midkine increases diagnostic yield in AFP negative and NASH-related hepatocellular carcinoma. PLoS One 11(5): e0155800, 2016. PMID: 27219517. DOI: 10.1371/journal.pone. 0155800

69 Zhang Y, Tang J, Zhou X, Zhu SL and Li LQ: Diagnostic accuracy of midkine for hepatocellular carcinoma: A metaanalysis. Mol Genet Genom Med 8(2): e1071, 2020. PMID: 31777190. DOI: $10.1002 / \mathrm{mgg} 3.1071$

70 N Zekri AR, el Kassas M, Salam ESTA el, Hassan RM, Mohanad M, Gabr RM, Lotfy MM, Abdel-Zaher RAT, Bahnassy AA and Ahmed OS: The possible role of Dickkopf-1, Golgi protein- 73 and Midkine as predictors of hepatocarcinogenesis: a review and an Egyptian study. Sci Rep 10(1): 5156, 2020. PMID: 32198440. DOI: 10.1038/s41598-020-62051-6

71 Bertino G, Ardiri AM, Calvagno GS, Bertino N and Boemi PM: Prognostic and diagnostic value of des- $\gamma$-carboxy prothrombin in liver cancer. Drug News Perspect 23(8): 498-508, 2010. PMID: 21031166. DOI: 10.1358/dnp.2010.23.8.1444236

72 De J, Shen Y, Qin J, Feng L, Wang Y and Yang L: A systematic review of des- $\gamma$-carboxy prothrombin for the diagnosis of primary hepatocellular carcinoma. Medicine (Baltimore) 95(17): e3448, 2016. PMID: 27124038. DOI: 10.1097/MD.0000000000003448

73 Lok AS, Sterling RK, Everhart JE, Wright EC, Hoefs JC, di Bisceglie AM, Morgan TR, Kim HY, Lee WM, Bonkovsky HL and Dienstag JL: Des- $\gamma$-carboxy prothrombin and $\alpha$-fetoprotein as biomarkers for the early detection of hepatocellular carcinoma. Gastroenterology 138(2): 493-502, 2010. PMID: 19852963. DOI: 10.1053/j.gastro.2009.10.031

74 Yang JD, Addissie BD, Mara KC, Harmsen WS, Dai J, Zhang N, Wongjarupong N, Ali HM, Ali HA, Hassan FA, Lavu S, Cvinar JL, Giama NH, Moser CD, Miyabe K, Allotey LK, AlgecirasSchimnich A, Theobald JP, Ward MM, Nguyen MH, Befeler AS, Reddy KR, Schwartz M, Harnois DM, Yamada H, Srivastava S, Rinaudo JA, Gores GJ, Feng Z, Marrero JA and Roberts LR: GALAD score for hepatocellular carcinoma detection in comparison with liver ultrasound and proposal of Galadus score. Cancer Epidemiol Biomarkers Prev 28(3): 531-538, 2019. PMID: 30464023. DOI: $10.1158 / 1055-9965$.EPI-18-0281

75 Berhane S, Toyoda H, Tada T, Kumada T, Kagebayashi C, Satomura S, Schweitzer N, Vogel A, Manns MP, Benckert J, Berg T, Ebker M, Best J, Dechêne A, Gerken G, Schlaak JF, Weinmann A, Wörns MA, Galle P, Yeo W, Mo F, Chan SL, 
Reeves H, Cox $\mathrm{T}$ and Johnson P: Role of the GALAD and BALAD-2 Serologic models in diagnosis of hepatocellular carcinoma and prediction of survival in patients. Clin Gastroenterol Hepatol 14(6): 875-886.e6, 2016. PMID: 26775025. DOI: $10.1016 /$ j.cgh.2015.12.042

76 Sengupta S and Parikh ND: Biomarker development for hepatocellular carcinoma early detection: current and future perspectives. Hepat Oncol 4(4): 111-122, 2017. PMID: 30191058. DOI: 10.2217/hep-2017-0019

77 Marrero JA, Feng Z, Wang Y, Nguyen MH, Befeler AS, Roberts LR, Reddy KR, Harnois D, Llovet JM, Normolle D, Dalhgren J, Chia D, Lok AS, Wagner PD, Srivastava S and Schwartz M: Alpha-fetoprotein, des-gamma carboxyprothrombin, and lectinbound alpha-fetoprotein in early hepatocellular carcinoma. Gastroenterology 137(1): 110-118, 2009. PMID: 19362088. DOI: $10.1053 /$ j.gastro.2009.04.005

78 Tzartzeva K, Obi J, Rich NE, Parikh ND, Marrero JA, Yopp A, Waljee AK and Singal AG: Surveillance imaging and alpha fetoprotein for early detection of hepatocellular carcinoma in patients with cirrhosis: A meta-analysis. Gastroenterology 154(6): 1706-1718.e1, 2018. PMID: 29425931. DOI: $10.1053 /$ j.gastro.2018.01.064

79 Yang JD, Dai J, Singal AG, Gopal P, Addissie BD, Nguyen MH, Befeler AS, Reddy KR, Schwartz M, Harnois DM, Yamada H, Gores GJ, Feng Z, Marrero JA and Roberts LR: Improved performance of serum alpha-fetoprotein for hepatocellular carcinoma diagnosis in hev cirrhosis with normal alanine transaminase. Cancer Epidemiol Biomarkers Prev 26(7): 10851092, 2017. PMID: 28258053. DOI: 10.1158/1055-9965.EPI-160747

80 Liu $\mathrm{X}$, Meng $\mathrm{J}, \mathrm{Xu} \mathrm{H}$ and Niu J: Alpha-fetoprotein to transaminase ratio is related to higher diagnostic efficacy for hepatocellular carcinoma. Medicine (Baltimore) 98(17): e15414, 2019. PMID: 31027143 . DOI: 10.1097/MD.0000000000015414

81 Zhang J, Chen G, Zhang P, Zhang J, Li X, Gan D, Cao X, Han $\mathrm{M}, \mathrm{Du} \mathrm{H}$ and Ye Y: The threshold of alpha-fetoprotein (AFP) for the diagnosis of hepatocellular carcinoma: A systematic review and meta-analysis. PLoS One 15(2): e0228857, 2020. PMID: 32053643. DOI: $10.1371 /$ journal.pone. 0228857
82 Merani S, Majno P, Kneteman NM, Berney T, Morel P, Mentha $\mathrm{G}$ and Toso $\mathrm{M}$ : The impact of waiting list alpha-fetoprotein changes on the outcome of liver transplant for hepatocellular carcinoma. J Hepatol 55(4): 814-819, 2011. PMID: 21334400. DOI: $10.1016 /$ j.jhep.2010.12.040

83 Duvoux C, Roudot-Thoraval F, Decaens T, Pessione F, Badran H, Piardi T, Francoz C, Compagnon P, Vanlemmens C, Dumortier J, Dharancy S, Gugenheim J, Bernard PH, Adam R, Radenne S, Muscari F, Conti F, Hardwigsen J, Pageaux GP, Chazouillères O, Salame E, Hilleret MN, Lebray P, Abergel A, Debette-Gratien M, Kluger MD, Mallat A, Azoulay D, Cherqui D and Liver Transplantation French Study Group: Liver transplantation for hepatocellular carcinoma: A model including $\alpha$-fetoprotein improves the performance of milan criteria. Gastroenterology 143(4): 986-94.e3, 2012. PMID: 22750200. DOI: $10.1053 /$ j.gastro.2012.05.052

84 Hameed B, Mehta N, Sapisochin G, Roberts JP and Yao FY: Alpha-fetoprotein level $>1000 \mathrm{ng} / \mathrm{mL}$ as an exclusion criterion for liver transplantation in patients with hepatocellular carcinoma meeting the Milan criteria. Liver Transpl 20(8): 945951, 2014. PMID: 24797281. DOI: 10.1002/lt.23904

85 Halazun KJ, Tabrizian P, Najjar M, Florman S, Schwartz M, Michelassi F, Benjamin Samstein B, Brown-Jr RS, Emond JC, Busuttil RW and Agopian VA: Is it time to abandon the Milan criteria? Results of a bicoastal US collaboration to redefine hepatocellular carcinoma liver transplantation selection policies. Ann Surg 268(4): 690-699, 2018. PMID: 30048307. DOI: 10.1097/SLA.0000000000002964

86 Mintz Y and Brodie R: Introduction to artificial intelligence in medicine. Minim Invasive Ther Allied Technol 28(2): 73-81, 2019. PMID: 30810430. DOI: 10.1080/13645706.2019.1575882

87 Hashimoto DA, Rosman G, Rus D and Meireles OR: Artificial intelligence in surgery: Promises and perils. Ann Surg 268(1): 7076, 2018. PMID: 29389679. DOI: 10.1097/SLA.00000000 00002693

Received October 12, 2020

Revised October 21, 2020

Accepted October 22, 2020 